\title{
Gold Nanoparticle Size Controlled by Polymeric Au(I) Thiolate Precursor Size
}

\author{
Raymond P. Briñas, Minghui Hu, Luping Qian, Elena S. Lymar, and James F. Hainfeld \\ Biology Department, Brookhaven National Laboratory, Upton, NY 11973, USA
}

\section{Abstract}

We developed a method in preparing size-controllable gold nanoparticles (Au NPs, 2-6 nm) capped with glutathione by varying the $\mathrm{pH}$ (between 5.5 and 8.0) of the solution before reduction. This method is based on the formation of polymeric nanoparticle precursors, $\mathrm{Au}(\mathrm{I})$-glutathione polymers, which change size and density depending on the $\mathrm{pH}$. Dynamic light scattering, size exclusion chromatography, and UV-vis spectroscopy results suggest that lower $\mathrm{pH}$ values favor larger and denser polymeric precursors and higher $\mathrm{pH}$ values favor smaller and less dense precursors. Consequently, the larger precursors led to the formation of larger Au NPs, whereas smaller precursors led to the formation of smaller Au NPs. Using this strategy, Au NPs functionalized with nickel (II) nitriloacetate (Ni-NTA) group were prepared by a mixed-ligand approach. These Ni-NTA functionalized Au NPs exhibited specific binding to 6x-histidine-tagged Adenovirus serotype 12 knob proteins, demonstrating their utility in biomolecular labeling applications.

\section{Introduction}

Controlling the size of nanoparticles (NPs) has always been one of the challenges in colloidal science. Changing the size of NPs can result in modulating of their physical and chemical properties. Au NPs have been a good candidate for applications in drug delivery, ${ }^{1}$ cell imaging, 2 and immobilization of proteins for conformational studies, ${ }^{3}$ among others. Since the discovery of various reducing agents for the gold compounds to form the gold nanoparticles, like sodium citrate, sodium borohydride, phosphorus, alcohols, tannic acid/citrate mixtures, the synthesis and applications of Au NPs of different sizes have flourished. ${ }^{4}$ More recently, several techniques that focus on the size control via the reduction of tetrachloroauric acid $\left(\mathrm{HAuCl}_{4}\right)$ were introduced. These include varying the gold to thiol ratio, ${ }^{5}$ varying the reaction temperature, ${ }^{6}$ varying the $\mathrm{pH}$ by varying the concentration of sodium citrate (reducing agent) 7 , sonochemical ${ }^{8}$ and sonoelectrochemical methods, ${ }^{9}$ seeding methods, ${ }^{10}$ the use of mixed reverse micelles, ${ }^{11}$ photochemical methods ${ }^{12}$ and the use of polymeric ligands such as block copolymers. ${ }^{13}$

Formation of Au NPs via the reduction of $\mathrm{HAuCl}_{4}$ in the presence of the thiol ligand has been a widely used technique in preparing ligand-stabilized Au NPs. ${ }^{14}$ Schiffrin and coworkers proposed a two-step mechanism for the formation of Au NP from $\mathrm{HAuCl}_{4} \cdot 15$ The first step involves the conversion of $\mathrm{Au}(\mathrm{III})$ salt to the $\mathrm{Au}(\mathrm{I})$ state (as thiolate salt). The $\mathrm{Au}(\mathrm{I})$ thiolate at this point is in a polymeric form. The second step involves the reductive decomposition of the polymeric $\mathrm{Au}(\mathrm{I})$ thiolate to form the NP. Although this method has been extensively used, its mechanistic details have not been elucidated. ${ }^{14}$ One of the most intriguing steps is the formation of polymeric $\mathrm{Au}(\mathrm{I})$ thiolate or the NP precursor. Exploration of this step could lead to clues on how to control the size of the resulting NPs, since the properties of the polymeric 
precursor are dependent on several factors, such as the nature of ligand, ionic strength, solvent conditions, and $\mathrm{pH}$. The variation in the polymeric structure by the nature of the ligand has been well documented in related compounds, such as gold based antiarthritic agents. ${ }^{16-18}$ For example, Myocrisin assumes a small cyclic structure (tetrameric) due to the repulsive force brought about by the carboxylate groups in adjacent ligands. 16

Choosing the right ligand for NP synthesis is key in forming Au NPs with desirable properties. In this study, we chose the naturally occurring peptide ligand, glutathione (GSH). GSH is a ubiquitous tripeptide ( $\gamma$-Glu-Cys-Gly), which acts primarily as a reducing agent in biological systems. Because of the favorable properties such as the presence of thiol, carboxylic acid and amino groups, water-solubility at relevant biological $\mathrm{pH}$, biological compatibility, and ease of functionalization, GSH is a very attractive ligand in making water-soluble NPs for biological applications. The presence of carboxylic acid and amino groups on GSH ligand complexed with $\mathrm{Au}(\mathrm{I})$ has the potential advantage of being a $\mathrm{pH}$-sensitive compound, which can adopt different conformational states and sizes depending on the $\mathrm{pH}$ of solution.

The first reported use of GSH as a ligand for Au clusters was by Hainfeld and coworkers 19 and further studied by Whetten and coworkers in $1998 .^{20,21}$ Whetten et al. synthesized the $\mathrm{Au}$ NPs via sodium borohydride reduction of the mixture of tetrachloroauric acid and GSH in methanol-water (2:3) and obtained Au NPs with most abundant component having a diameter of $0.9 \mathrm{~nm}$. Tsukuda and coworkers conducted a more extensive electrophoretic separations and high resolution mass spectrometric analyses of the Au NPs, prepared in a similar manner as that of the Whetten's study, to reveal the varied size composition of the NP mixture (i.e. $\mathrm{Au}_{10}(\mathrm{SG})_{10}, \mathrm{Au}_{15}(\mathrm{SG})_{13}, \mathrm{Au}_{18}(\mathrm{SG})_{14} \ldots$ ) depending on the reaction temperature (low or room temperature). ${ }^{22,23}$ In both studies, the size of the NPs formed was between $0.8 \mathrm{~nm}$ and 1.1 $\mathrm{nm}$. Although the preparation of the Au NPs was well-established and the composition of the Au NPs was extensively characterized, the issues of size controllability and further functionalization of the Au NPs to suit particular applications, such as biomolecular labeling, were not addressed in these studies. These issues are very important especially for the utility of the Au NPs in applications that require functionality and size control. Herein, we report a technique for which the size of the Au NPs coated with GSH can be controlled by varying the size of the nanoparticle precursor $[\mathrm{Au}(\mathrm{I}) \mathrm{SG}]$ through $\mathrm{pH}$ control. The size of the final NPs can be varied from 2 to $6 \mathrm{~nm}$. Furthermore, functionalization of Au NPs coated with GSH is demonstrated by the introduction of nitrilotriacetic acid (NTA) moiety by mixing another ligand (i.e. NTA-Lysine modified ligand) with GSH. To demonstrate the utility of the sizecontrollable Ni-NTA-functionalized Au NP in the 2-6 nm size regime, a biomolecule, adenovirus serotype 12 (Ad12) knob expressed with 6x-histidine (His) tags, is labeled with 4.4 $\mathrm{nm} \mathrm{Au}$ NP and analyzed by size exclusion chromatography (SEC) and transmission electron microscopy (TEM).

Ad12 knob protein is a globular knob-like domain located at the ends of trimeric fibers protruding from the adenovirus capsid. It acts as the initiating point for virus infection upon interactions with specific receptors on host cell surfaces. ${ }^{24}$ The Ad12 knob proteins exist as a trimer with a total molecular weight (MW) of about $60 \mathrm{kDa}$ (Figure $1 \mathrm{~A}$ ). It has $\mathrm{C}_{3}$ symmetry with the His-tagged N-termini clustered near each other (Figure 1B). There are, therefore, three His-tags in close proximity. Our synthesized Ni-NTA functionalized Au NPs show highly specific binding to His tags on Ad12 knob proteins. Labeling of biomolecules with Au NPs is attracting more interests in applications like high-resolution structural analysis, ${ }^{25}$ medical imaging, ${ }^{26}$ and molecular sensing. 27 These applications require functionalized Au NPs with physical/chemical stability, water solubility, biological compatibility, and site-specific binding. 28,29 


\section{Experimental Section}

\section{General Remarks}

$\mathrm{HAuCl}_{4} \cdot \mathrm{XH}_{2} \mathrm{O}$ was purchased from Strem Chemicals and used as received. Reduced glutathione (GSH), sodium borohydride, $\mathrm{N}^{6}$-carbobenzyloxy-L-lysine, and 4butyrothiolactone were purchased from Sigma and used as received. UV-Vis spectra were recorded on Agilent 8453 spectrophotometer. TEM specimens were prepared by evaporating sample solutions on plasma-treated $\mathrm{Cu}$ mesh grids covered with carbon thin films. Nano-W (Nanoprobes, Inc.) solution was used for negative stain samples. TEM images were taken using a JEM $1200 \mathrm{CX}$ (JEOL) operating at $120 \mathrm{kV}$ at low dose $\left(<10 \mathrm{e} / \AA^{2}\right)$ with a $1 \mathrm{k} \times 1 \mathrm{k} C \mathrm{CD}$ camera (Gatan). The sizes of Au NPs were analyzed with TEM images using ImageJ (NIH). The dynamic light scattering (DLS) data were recorded on a Precision Detectors PD 2000 DLS Plus with CoolBatch 40T. The hydrodynamic radii of polymeric Au(I)SG solutions were analyzed using Precision Deconvolve 32 software.

\section{General Procedure for the Preparation of Au NP coated with GSH}

An aqueous solution of tetrachloroauric acid $\left(\mathrm{HAuCl}_{4} \cdot \mathrm{XH}_{2} \mathrm{O}, 1 \mathrm{~mL}, 0.025 \mathrm{M}\right)$ was mixed with an aqueous solution of GSH $(7.8 \mathrm{~mL}, 0.019 \mathrm{M})$. The $\mathrm{pH}$ of the resulting mixture was adjusted between 5.3 and 8.0 using $1 \mathrm{M} \mathrm{NaOH}$. A freshly prepared $\mathrm{NaBH}_{4}$ solution $(2 \mathrm{mg} / \mathrm{mL}$ in water, 10 -fold molar excess) was added with stirring. The mixture was allowed to react overnight at room temperature. The excess reactants were removed by size exclusion chromatography (GH-25, water) and the gold cluster fraction was collected and concentrated by centrifugal filtration (Molecular weight cutoff or MWCO 50kDa, Millipore Amico Ultra).

\section{Synthesis of Lys-NTA-SH}

Lys-NTA-SH ((1S)-N-[5-[(4-Mercaptobutanoyl)amino]-1 carboxypentyl]iminodiacetic acid) was synthesized using a modified literature procedure. ${ }^{30-32}$ Briefly, $\mathrm{N}^{6}$-carbobenzyloxy-Llysine ( $\mathrm{Lys}(\mathrm{Z}) \mathrm{OH})$ was reacted with bromoacetic acid under basic conditions to form Lys(Z)NTA (Scheme 1). Lys(Z)-NTA was then deprotected by hydrogenolysis in $210 \mathrm{~mL}$ of 20:1 THF-water mixture (instead of the reported 20:1 methanol-water mixture ${ }^{30,31}$ ) under $1 \mathrm{~atm}$ of $\mathrm{H}_{2}$ for $20 \mathrm{~h}$ to give Lys-NTA. Reaction of Lys-NTA with 4-butyrothiolactone gave the desired product Lys-NTA-SH in $61 \%$ yield $(1.0 \mathrm{~g})$.

\section{Representative Procedure for the preparation of Au-GSH/Lys-NiNTA}

A solution of Lys-NTA-SH $(8 \mathrm{mg}, 0.022 \mathrm{mmol})$ in water $(1.3 \mathrm{ml})$ was mixed with a solution of GSH (20 mg, $0.066 \mathrm{mmol})$ in water $(3.4 \mathrm{ml})$. The mixed solution was added to a solution of hydrogen tetrachloroaurate ( $\mathrm{HAuCl} 4,5 \mathrm{mg}, 0.015 \mathrm{mmol})$ in water $(0.5 \mathrm{ml})$, followed by adjusting the $\mathrm{pH}$ to $6.0-6.5$ with $1 \mathrm{M} \mathrm{NaOH}$. A solution of sodium borohydride (5.6 $\mathrm{mg}, 0.15$ $\mathrm{mmol}$ ) in water $(2.8 \mathrm{ml})$ was added with vigorous stirring for $10 \mathrm{~min}$ at r.t and the mixture was allowed to react overnight. The Au NPs were purified by gel filtration chromatography (GH-25, water), followed by centrifugal concentration with Centri-prep filter (MWCO 30kDa, Millipore Amico Ultra). The resulting solution was passed through a cation exchange column (CM-Sepharose, Pharmacia) pre-treated with $0.05 \mathrm{M} \mathrm{NiCl}_{2}$ solution. The colored band was collected and used for the next step.

\section{Labeling of Histidine-tagged Ad12 Knob Proteins}

To a solution of His-tagged Ad12 knob proteins $(24 \mu \mathrm{l}, 1 \mathrm{mg} / \mathrm{ml})$ at pH 7.5 containing $10 \mathrm{mM}$ phosphate buffered saline (PBS, $150 \mathrm{mM} \mathrm{NaCl}$ ) was added an aqueous solution of Ni-NTA functionalized Au NPs $(40 \mu \mathrm{l}, 1 \mu \mathrm{M})$ with an average size of $4.4 \mathrm{~nm}$. The mixed solution was incubated at r.t. for $3 \mathrm{~min}$. The crude mixture was purified by SEC (Superdex 200, Eluant: 10 
mM PBS, $140 \mathrm{mM} \mathrm{NaCl}, \mathrm{pH}$ 7.4) and the labeled fractions were collected and analyzed by TEM.

\section{Dynamic Light Scattering Measurements for the polymeric Au(I)SG}

Aqueous solutions of $\mathrm{HAuCl}_{4}(10 \mathrm{mg} / \mathrm{mL})$ and $\mathrm{GSH}(6 \mathrm{mg} / \mathrm{ml})$ were filtered separately through syringe filters $(0.22 \mu \mathrm{m}$ PVDF membrane, Millipore) prior to mixing. To a stirred solution of $\mathrm{HAuCl}_{4}(0.5 \mathrm{~mL})$ was added $\mathrm{GSH}$ solution $(4.5 \mathrm{~mL})$. The resulting mixture was stirred for $1-2$ $\mathrm{min}$. The $\mathrm{pH}$ of the mixture was adjusted to 4.92 by adding $1 \mathrm{M} \mathrm{NaOH}$. The mixture was filtered through a syringe filter ( $0.45 \mu \mathrm{m}$ PVDF membrane, Millipore) before measuring the DLS. Mixtures with $\mathrm{pH}$ values of 5.08, 5.55, 6.16, 7.25 and 8.11 were also prepared and analyzed using the same procedure as above.

\section{Size Exclusion Chromatographic Analysis of the polymeric $\mathrm{Au}(\mathrm{I}) \mathrm{SG}$ at different pH values}

The polymeric $\mathrm{Au}(\mathrm{I}) \mathrm{SG}$ samples at different $\mathrm{pH}$ values $(4.8,6.4$, and 7.9$)$ were prepared in a similar manner as described above for the DLS samples, but without filtering the solutions. The polymeric solutions ( $200 \mu \mathrm{L}$ per injection) were analyzed by SEC-HPLC using Superose 6 column and either $10 \mathrm{mM}$ PBS with $150 \mathrm{mM} \mathrm{NaCl}$ (pH 6.4 or 7.9) or $10 \mathrm{mM}$ acetate buffer with $150 \mathrm{mM} \mathrm{NaCl}(\mathrm{pH} 4.8)$ as the eluting solvent.

\section{Results and Discussion}

The Au NPs were synthesized employing a three-step procedure (Scheme 2A). The first step involves the reaction between the $\mathrm{GSH}$ and $\mathrm{HAuCl}_{4}(6: 1$ molar ratio), the second step involves the adjustment of $\mathrm{pH}$ of the mixture from the first step. Lastly, the Au NPs (1) are formed by addition of $\mathrm{NaBH}_{4}$. This method can be extended to the synthesis of Au NPs with mixed ligands (Scheme 2B). For example, a mixture of GSH and Lys-NTA-SH in the 3:1 molar ratio was used to prepare NTA-functionalized Au NP (2) used in this study for biomolecular labeling.

Au NPs coated with GSH (1) were synthesized at various $\mathrm{pH}$ values of the pre-borohydride reduced solutions (mixture of $\mathrm{HAuCl}_{4}$ and ligand). The final Au NPs are stable and can be stored at $4^{\circ} \mathrm{C}$ for three months without aggregation. The change in size of the Au NPs as the $\mathrm{pH}$ changes was monitored using UV-vis spectroscopy. There was a blue shift in the conspicuous surface plasmon resonance band from 532 to $507 \mathrm{~nm}$ as the $\mathrm{pH}$ value was increased from 5.5 to 8.0 (See Figure S1, Supporting Information), indicating that the Au NP size decreases as the $\mathrm{pH}$ increases. The exact sizes of $\mathbf{1}$ were analyzed from the TEM micrographs (Figure 2), and plotted with the $\mathrm{pH}$ values as shown in Figure 3. The sizes decreased from 6 to $2 \mathrm{~nm}$ with standard deviations of $20-30 \%$ as the $\mathrm{pH}$ values increased from 5.3 to 8.0.

The same trend is followed when a mixed ligand of 3:1 molar ratio of GSH/Lys-NTA-SH is used, as shown by hollow squares at $\mathrm{pH} 6$ and 8 (Figure 3). Combining GSH with Lys-NTASH to form a mixed-ligand Au NP (2) was done in order to functionalize the Au NP and to use as a site-specific labeling agent for electron microscopy applications. A mixture of 3:1 molar ratio of GSH to Lys-NTA-SH proved to be the optimal condition wherein stable clusters with spherical shapes were formed and the size dependence on $\mathrm{pH}$ was maintained. This indicates the controllability of the size even in the presence of another ligand by varying the $\mathrm{pH}$ of the pre-reduction solution. The effect of the excess GSH ligand was determined by performing control experiments. Before borohydride reduction, the mixture of $\mathrm{HAuCl}_{4}$ and $\mathrm{GSH}$ (1:6 molar ratio, $\mathrm{pH}$ 8) was filtered using Centricon Ultrafilter (MWCO 5kDa) and washed with water to remove the excess GSH. Dilution of the retentate to the original volume and subsequent reduction with sodium borohydride gave a spectrum similar to that of the "unfiltered" solution (Figure S2, Supporting Information). This indicates that any excess GSH has negligible effect on the size of the resulting Au NP. 
The formation of nanoparticle 1 follows the general mechanism proposed previously for the formation of $\mathrm{Au} \mathrm{NP}$ from $\mathrm{Au}^{3+}$ and thiols. ${ }^{15,20,33}$ In this mechanism (Scheme 3), $\mathrm{Au}^{3+}$ is reduced by GSH first to $\mathrm{Au}^{+1}$. The $\mathrm{Au}^{+1}$ then forms a polymeric structure ([Au(I)SG $]_{\mathrm{n}}$ ), where $\mathrm{Au}^{+1}$ ions have a coordination number of 2 and are bridged by the thiolate sulfur atom of GSH. 16,34 Addition of sodium borohydride solution decomposes the polymeric structure to form the Au NP.

The second equation is the key step in this study because the size of the polymer was found to be $\mathrm{pH}$ dependent. The polymeric structure of $\mathrm{Au}(\mathrm{I})$ thiolates, including $\mathrm{Au}(\mathrm{I}) \mathrm{SG}$ and goldbased anti-arthritic agents, has been established and extensively studied in the past using Mössbauer spectroscopic techniques. ${ }^{34}$ Although the X-ray structures of some Au(I) thiolates have been solved, that of [Au(I) SG] polymer is yet to be determined. It is likely that the $\mathrm{Au}$ (I)SG polymers exist in random coils consistent with these precedent data.

To further characterize the structure the precursor $\mathrm{Au}(\mathrm{I}) \mathrm{SG}$ polymers, their relative sizes and spectroscopic behavior were studied at different $\mathrm{pH}$ values. The presence of polymeric structures with different sizes at different $\mathrm{pH}$ values was followed by DLS. The results of a mixture of $\mathrm{HAuCl}_{4}$ and $\mathrm{GSH}$ (1:6 molar ratio) at various $\mathrm{pH}$ values (Figure $4 \mathrm{~A}$ ) reveal that the average hydrodynamic radius of the polymeric gold species decreases with increasing $\mathrm{pH}$ values. SEC analysis of the polymeric precursors at different $\mathrm{pH}$ values confirmed the DLS results (Figure 4B). At low pH (4.8), the mixture is composed of predominantly larger polymeric structures as indicated by the presence of a faster-moving peak with a retention time of $22.9 \mathrm{~min}$, which could be attributed to larger polymers. At moderate $\mathrm{pH}(6.4)$, the mixture is possibly composed of a combination of larger and smaller polymers, as evident in the broad peak centered at $23.4 \mathrm{~min}$. Lastly, at high $\mathrm{pH}$ (7.9), a slower-moving peak (retention time of $23.7 \mathrm{~min}$ ) could be attributed to smaller polymers. The excess GSH apparently had no effect on the size of the polymeric precursors. A 1:6 mixture of $\mathrm{HAuCl}_{4}$ and $\mathrm{GSH}$ at $\mathrm{pH} 8$ was filtered using Centricon Utrafilter (MWCO 5kDa) and washed with water to remove excess GSH. The hydrodynamic radius of the original solution $(24.5 \pm 2.8 \mathrm{~nm})$ and the filtered one gave a similar size $(26.5 \pm 2.7 \mathrm{~nm})$, indicating that GSH has no effect on the size of the polymers.

The structural changes in the polymeric precursors can be studied by analyzing the interaction of adjacent $\mathrm{Au}(\mathrm{I})$ ions using UV-Vis spectroscopy. A UV-vis spectroscopic investigation of the mixture of tetrachloroauric acid and GSH in 1:6 molar ratio at different $\mathrm{pH}$ values showed an absorption at $\sim 320 \mathrm{~nm}$ (shoulder) that diminishes in intensity as the $\mathrm{pH}$ increases (Figure 5). This band could be assigned to the $\mathrm{d}_{\sigma^{*} \rightarrow} \mathrm{p}_{\sigma}$ transition similar to that observed for diphosphine bridged binuclear $\mathrm{Au}(\mathrm{I})$ complexes, ${ }^{35-39}$ which is an indication of metal-metal interaction. At higher $\mathrm{pH}$ values (6-8), the $\mathrm{d}_{\sigma^{*}} \rightarrow \mathrm{p}_{\sigma}$ absorption band is shifted and considerably smaller but still monotonically changes with $\mathrm{pH}$. At lower $\mathrm{pH}$ values (4.72-5.57), the higher intensity of the band suggests the increased presence of metal-metal interactions. The $\mathrm{pH}$ range going from 4.7 to 6.0 gave the highest decrease in the intensity of the metal-metal interaction band. In terms of the Au-S-Au angle ( $\varphi$ ), the UV-vis data indicates that a smaller angle is favored at lower $\mathrm{pH}$ and a larger angle at higher $\mathrm{pH}$ (Scheme 4). This also implies that denser polymers are formed at low $\mathrm{pH}$ and less dense at high $\mathrm{pH}$.

On the basis of the UV-Vis data and results from the DLS and SEC studies, we hypothesize that at lower $\mathrm{pH}$ the polymeric precursors have larger and denser structures, while at higher $\mathrm{pH}$ the polymeric precursors assume less dense and smaller structures. This could be a consequence of the strength of repulsive electrostatic forces acting between neighboring GSH ligands (Scheme 4). GSH can have four ionization forms (Scheme 5, A-E), since it has four ionizable functional groups (one ammonium group, two carboxylic acid groups, and one thiol group). The first $\left(\mathrm{pK}_{1}=2.12\right)^{40}$ and second $\left(\mathrm{pK}_{2}=3.53\right)^{40}$ ionizations can be ignored because their $\mathrm{pK}_{\mathrm{a}}$ values are below the lowest $\mathrm{pH}$ value used in this study. Also, the ionization of the 
thiol group $\left(\mathrm{pK}_{4}=9.62\right)^{40}$ can be ignored because its $\mathrm{pKa}$ is above the highest $\mathrm{pH}$ value and coordination with $\mathrm{Au}(\mathrm{I})$ converted the thiol into the thiolate form. Thus, the major contributing species in the $\mathrm{pH}$ range of interest are species $\mathrm{C}$ and $\mathrm{D}$. At low $\mathrm{pH}$ (4.8), species $\mathrm{C}$ predominates over D and so the net charge on the GSH ligands is about -1 . On the other hand, at high $\mathrm{pH}$ (8.0), species D predominates over species $\mathrm{C}$ and the net charge of the ligand approaches -2 . At higher $\mathrm{pH}$ values, the monomeric units $(\mathrm{Au}(\mathrm{I}) \mathrm{SG})$ are negatively charged and so the growth of the polymer is limited by the stronger repulsive interaction; hence, only smaller and denser precursors are formed. At lower $\mathrm{pH}$ values, the monomeric units are able to approach a growing polymer due to the less repulsive force and so the precursors formed are larger and less dense.

Higher density of the $\mathrm{Au}(\mathrm{I}) \mathrm{SG}$ polymeric structures at lower $\mathrm{pH}$ values is also predicted (Scheme 4). The larger polymeric precursors at low pH lead to the formation of fewer nuclei for borohydride reduction to NPs (Scheme 6). Fewer nuclei which have more Au ions in close proximity result in larger Au NPs. This is consistent with the common principle that fewer nuclei lead to larger particles, since during the growth phase $\mathrm{Au}(\mathrm{I})$ is preferentially reduced onto an existing $\mathrm{Au}(0)$ surface rather than independently forming a new particle. Conversely, higher $\mathrm{pH}$ values favor a lower degree of polymerization of $\mathrm{Au}(\mathrm{I}) \mathrm{SG}$. Repulsive negative charges increase on the GSH ligand at higher $\mathrm{pH}$ values due the deprotonation of the ammonium group (pKa 8.66), ${ }^{40}$ thus favoring smaller polymeric structures or possibly monomeric $\mathrm{Au}(\mathrm{I})$ SG units. This results in the formation of more nuclei, hence leading to smaller NPs (Scheme $6)$.

This strategy gives an insight into the possibility of tailoring the desired properties such as size, solubility, and functionality of the NPs based on the structure of the ligand and its $\mathrm{Au}(\mathrm{I})$ thiolate form. For the size controllability, the structure of the ligand is key. By virtue of its carboxylic acid groups and amino group, GSH responds to the change in $\mathrm{pH}$ by changing its conformation due to the repulsive or attractive forces. The size controllability could be potentially extended to the use of ligands that can change conformation upon changing the temperature, or upon exposure to radiation, etc.

Because of the better visibility of larger gold nanoparticles (> $2 \mathrm{~nm}$ ) in EM, the $4.4 \mathrm{~nm} \mathrm{Au}$ NPs functionalized with Ni-NTA were used to label His-tagged Ad12 knob protein. The Au NPs used in this investigation were prepared from Au NPs capped with GSH/Lys-NTA-SH mixture (3:1 molar ratio), which was complexed with $\mathrm{Ni}^{2+}$ ion by passing through an ion exchange column pre-treated with a $\mathrm{NiCl}_{2}$ solution.

The binding of the Ni-NTA-functionalized Au NP with a His-tagged protein is governed by the formation of stable coordinate bonds between two imidazoles from two histidines of the His-tagged protein and the $\mathrm{Ni}^{2+}$ center of the Ni-NTA group of the Au NP through a ligand exchange mechanism (Scheme 7). Two water molecules are expelled in the process to maintain the octahedral coordination. Labeling of His-tagged Ad12 knob proteins with $4.4 \mathrm{~nm}$ Ni-NTA functionalized Au NPs was confirmed by SEC (see Figure S3 and note, Supporting Information for details of labeling experiment) and TEM analyses. The TEM micrograph of the labeledprotein fraction shows that there is indeed labeling of the Ad12 proteins as evident in the formation of core-shell structures (Figure 6A), which is a consequence of the multiple Ni-NTA functional groups on the surface of each Au NP. The number of knob proteins on the surface of Au NP is limited by steric hindrance. It is also worth mentioning that the binding efficiency of this labeling is very high because all of the Au NPs were encapsulated by the knob proteins.

To discount the possibility of nonspecific binding in the labeling experiment, a control experiment was done using Ad12 knob complexes without histidine tags. The absence of coreshell NP-protein structures in the control experiment (Figure 6B) indicates that Ad12 knob complexes without histidine tags do not bind to the Ni-NTA Au NP. This shows that binding 
of Ni-NTA Au NP to Ad12 knob protein is highly specific for the presence of histidine tag on the protein. Specific binding of NPs to biomolecules has proven to be an indispensable attribute in applications such as electrochemistry 41 , carbohydrate-protein recognition ${ }^{42}$, and DNAbased diagnostic applications. ${ }^{43}$

\section{Conclusion}

In conclusion, we have shown that GSH-capped Au NPs of various sizes, in the 2-6 nm size regime, can be prepared by controlling the $\mathrm{pH}$. The size controllability has been attributed to the dependence of the size of the Au NP precursor, $\mathrm{Au}(\mathrm{I}) \mathrm{SG}$, on $\mathrm{pH}$. The ligand, GSH, plays an important role in the size dependence on $\mathrm{pH}$. Not only does it impart water-solubility to the resulting NPs, but also modulates the size of the NP precursors through the attractive or repulsive forces acting on adjacent ligands at certain $\mathrm{pH}$ values. Lower $\mathrm{pH}$ values favored the formation of larger and denser polymeric precursors because of the weaker repulsive electrostatic forces, present between adjacent ligands. On the other hand, smaller and less dense polymeric precursors were present at higher $\mathrm{pH}$ values due to the stronger repulsive electrostatic forces of the carboxylate groups between adjacent ligands. The larger precursors lead to the formation of larger NPs, whereas smaller precursors lead to the formation of smaller NPs.

The NPs were functionalized by mixing together two types of ligands, GSH and modified lysine bearing the Ni-NTA moiety and a thiol linker. This approach paves the way to preparing $\mathrm{Au}$ NPs of various sizes and various functionalities without destroying the desirable properties of solubility and stability. The Ni-NTA functionalized Au NPs were shown to have specific binding to His-tagged Ad12 knob proteins. This labeling technique can have potential biological application in high-resolution structural analysis, medical imaging, drug delivery, molecular sensing, and scaffold-directed assembly where binding specificity and size of NPs are important.

\section{Supplementary Material}

Refer to Web version on PubMed Central for supplementary material.

\section{Acknowledgements}

We would like to thank Yanbiao Zhang and Paul I. Freimuth for providing the protein samples. We are grateful to Walter Mangel and Vito Graziano for use of their DLS machine. This work was supported by BNL LDRD Grant 04-055, DOE Grant 06742 and NIH Grants P41EB002181 and R01RR017545.

\section{References}

1. Salem AK, Searson PC, Leong KW. Nature Mater 2003;2:668-671. [PubMed: 12970757]

2. Shukla S, Priscilla A, Banerjee M, Bhonde RR, Ghatak J, Satyam PV, Sastry M. Chem Mater 2005;17:5000-5005.

3. Krämer S, Xie H, Gaff J, Williamson JR, Tkachenko AG, Nouri N, Feldheim DA, Feldheim DL. J Am Chem Soc 2004;126:5388-5395. [PubMed: 15113210]

4. Handley, DA. Colloidal Gold: Principles, Methods, and Applications. Hayat, MA., editor. 1. Academic Press, Inc.; San Diego: 1989. p. 13-30.

5. Frenkel AI, Nemzer S, Pister I, Soussan L, Harris T. J Chem Phys 2005;123:184701. [PubMed: 16292915]

6. Song JH, Kim YJ, Kim JS. Curr Appl Phys 2006;6:216-218.

7. Ji X, Song X, Li J, Bai Y, Yang W, Peng X. J Am Chem Soc. 200710.1021/ja074447kASAP Article

8. Mori Y, Kitamoto N, Tsuchiya K. J Chem Eng Jpn 2005;38:238-288.

9. Liu YC, Yu CC. J Electroanal Chem 2005;585:206-213. 
10. Sau TK, Pal A, Jana NR, Wang ZL, Pal T. J Nanoparticle Res 2001;3:257-261.

11. Chiang CL. J Colloid Interface Sci 2001;239:334-341. [PubMed: 11426997]

12. Pal A. Mater Lett 2004;58:529-534.

13. Sakai T, Alexandridis P. J Phys Chem B 2005;109:7766-7777. [PubMed: 16851902]

14. Templeton AC, Wuelfing WP, Murray RW. Acc Chem Res 2000;33:27-36. [PubMed: 10639073]

15. Brust M, Walker M, Bethell D, Schiffrin DJ, Whyman R. J Chem Soc, Chem Commun 1994:801802.

16. Brown K, Parish RV, McAuliffe CA. J Am Chem Soc 1981;103:4943-4945.

17. Bachman RE, Bodolosky-Bettis SA, Glennon SC, Sirchio SA. J Am Chem Soc 2000;122:7146-7147.

18. Bau R. J Am Chem Soc 1998;120:9380-9381.

19. Hainfeld, JF.; Leone, RD.; Furuya, FR.; Powell, RD. US Patent: 5,521,289. 1996.

20. Schaaff TG, Knight G, Shafigullin MN, Borkman RF, Whetten RL. J Phys Chem B 1998;102:1064310646.

21. Schaaff TG, Whetten RL. J Phys Chem B 2000;104:2630-2641.

22. Negishi Y, Takasugi Y, Sato S, Yao H, Kimura K, Tsukuda T. J Am Chem Soc 2004;126:6518-6519. [PubMed: 15161256]

23. Negishi Y, Nobusada K, Tsukuda T. J Am Chem Soc 2005;127:5261-5270. [PubMed: 15810862]

24. Bewley MC, Springer K, Zhang Y, Freimuth P, Flanagan JM. Science 1999;286:1579-1583. [PubMed: 10567268]

25. Rice S, Lin AW, Safer D, Hart CL, Naberk N, Carragher BO, Cain SM, Pechatnikova E, WilsonKubalek EM, Whittaker M, PateI E, Cookek R, Taylor EW, Milligan RA, Vale RD. Nature 1999;402

26. Hainfeld JF, Slatkin DN, Focella TM, Smilowitz HM. Br J Radiol 2006;79:248-253. [PubMed: 16498039]

27. Aubin ME, Hamad-Schifferli K. Langmuir 2005;21:12080-12084. [PubMed: 16342975]

28. Hainfeld JF, Powell RD. J Histochem Cytochem 2000;48:471-480. [PubMed: 10727288]

29. Hainfeld, JF.; Powell, RD. Molecular morphology in human tissues: techniques and applications. CRC Press; Boca Raton, FL: 2005.

30. Du Roure O, Debiemme-Chouvy C, Malthete J, Silberzan P. Langmuir 2003;19:4138-4143.

31. Schmitt L, Dietrich C, Tampé R. J Am Chem Soc 1994;116:8485-8491.

32. Hochuli E, Dobeli H, Schacher A. J Chromatogr 1987;411:177-184. [PubMed: 3443622]

33. Schaaff TG, Shafigullin MN, Khoury JT, Vezmar I, Whetten RL, Cullen WG, First PN. J Phys Chem B 1997;101:7885-7891.

34. Shaw CFI, Schaeffer NA, Elder RC, Eidsness MK, Trooster JM, Calis GHM. J Am Chem Soc 1984;106:3511-3521.

35. Leung KH, Phillips DL, Mao Z, Che CH, Miskowski VM, Chan CK. Inorg Chem 2002;41:20542059. [PubMed: 11952358]

36. Jaw HRC, Savas MM, Rogers RD, Mason WR. Inorg Chem 1989;28:1028-1037.

37. Jaw HRC, Savas MM, Mason WR. Inorg Chem 1989;28:4366-4369.

38. King C, Wang JC, Khan MNI, Fackler JP Jr. Inorg Chem 1989;28:2145-2149.

39. Che CH, Kwong HL, Poon CK, Yam VWW. J Chem Soc, Dalton Trans 1990:3215-3219.

40. Pirie NW, Pinhey KG. J Biol Chem 1929:321-333.

41. Kerman K, Chikae M, Yamamura S, Tamiya E. Anal Chim Acta 2007;588:26-33. [PubMed: 17386790]

42. Lin PC, Ueng SH, Yu SC, Jan MD, Adak AK, Yu CC, Lin CC. Org Lett 2007;9:2131-2134. [PubMed: 17477538]

43. Storhoff JJ, Marla SS, Bao P, Hagenow S, Mehta H, Lucas A, Garimella V, Patno T, Buckingham W, Cork W, Muller UR. Biosens Bioelectron 2004;19:875-883. [PubMed: 15128107] 
A

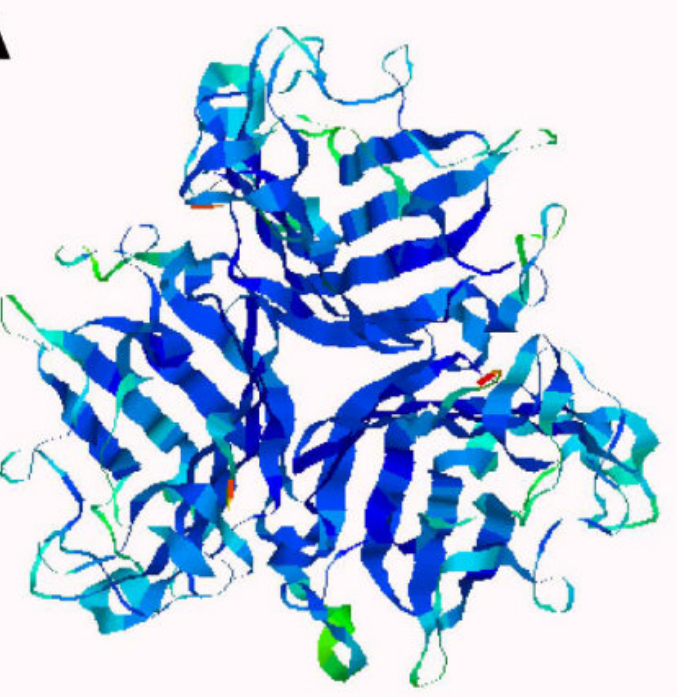

B

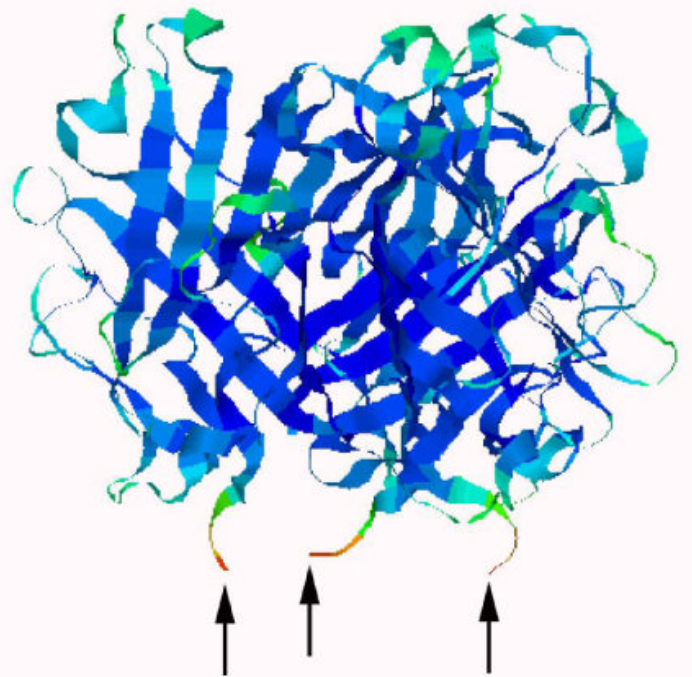

Figure 1.

Crystal structure of Ad12 knob protein showing the top view (A) and the side view (B) orientations (Reference 24). The arrows in B indicate the N-termini where His-tags were placed. 

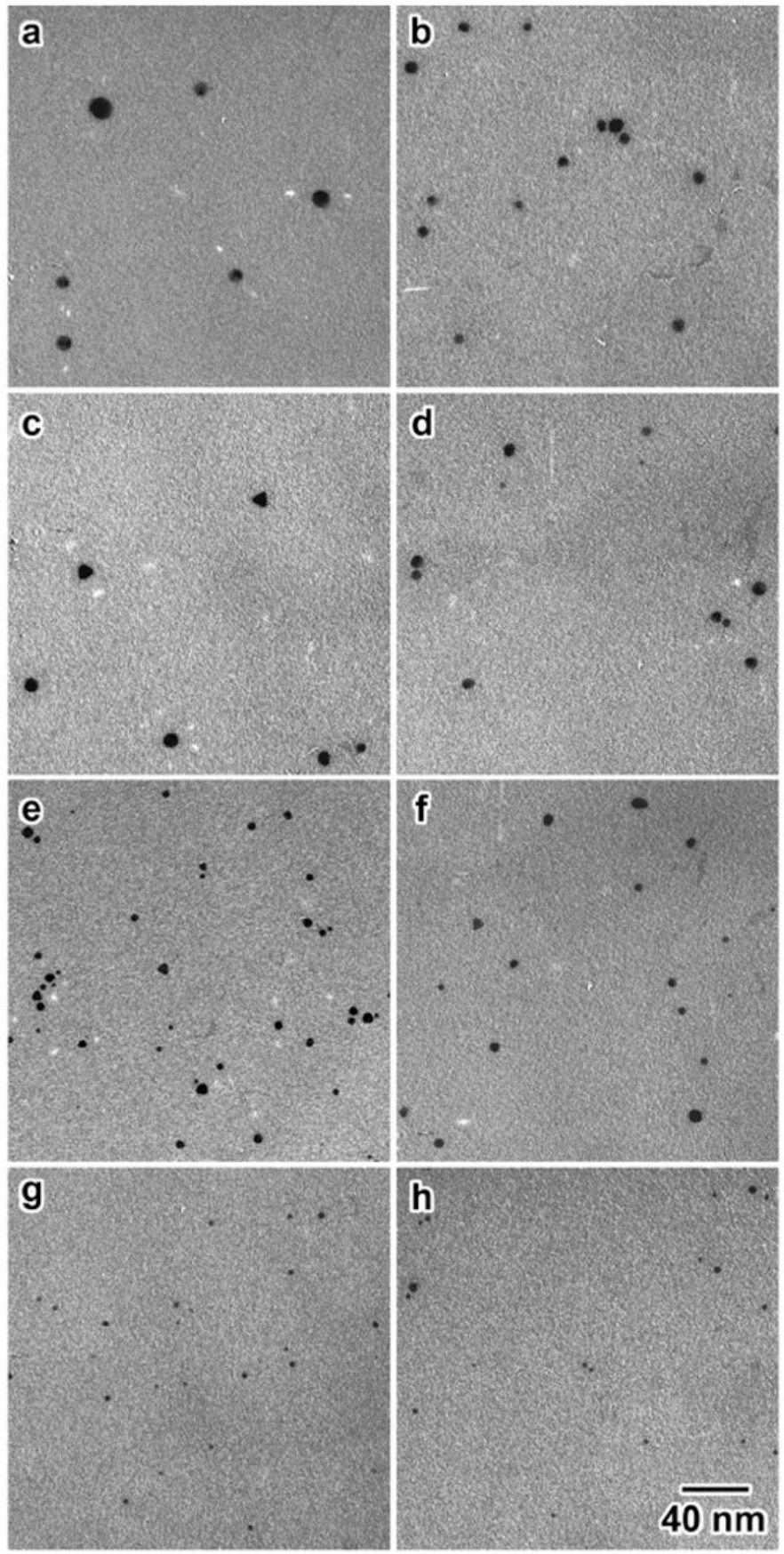

Figure 2.

TEM micrographs of the Au NP 1 synthesized at different $\mathrm{pH}$ values; in parentheses are the average sizes in nm. (a) 5.5 (6.3), (b) 6.1 (5.4), (c) 6.3 (4.7), (d) 6.5 (6.0), (e) 6.8 (3.6), (f) 7.0 (3.3), (g) 7.5 (2.6), (h) 8 (2.2). All of the micrographs are in the same scale. 


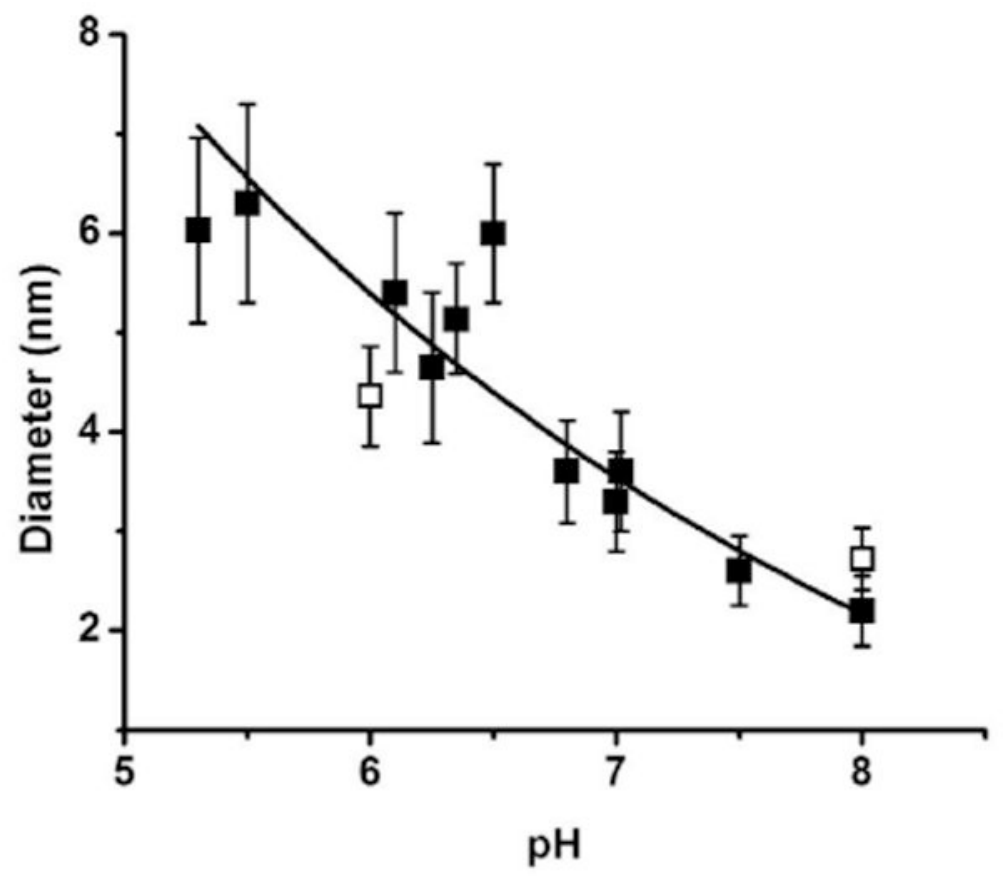

Figure 3.

Size dependence of the AuNP 1 with $\mathrm{pH}$ as measured by EM. Solid squares correspond to the average sizes of Au NP capped with GSH, while open squares represent the average sizes of $\mathrm{Au}$ NP 2. The error bars indicate the standard deviations. About one hundred particles were analyzed for each point. 

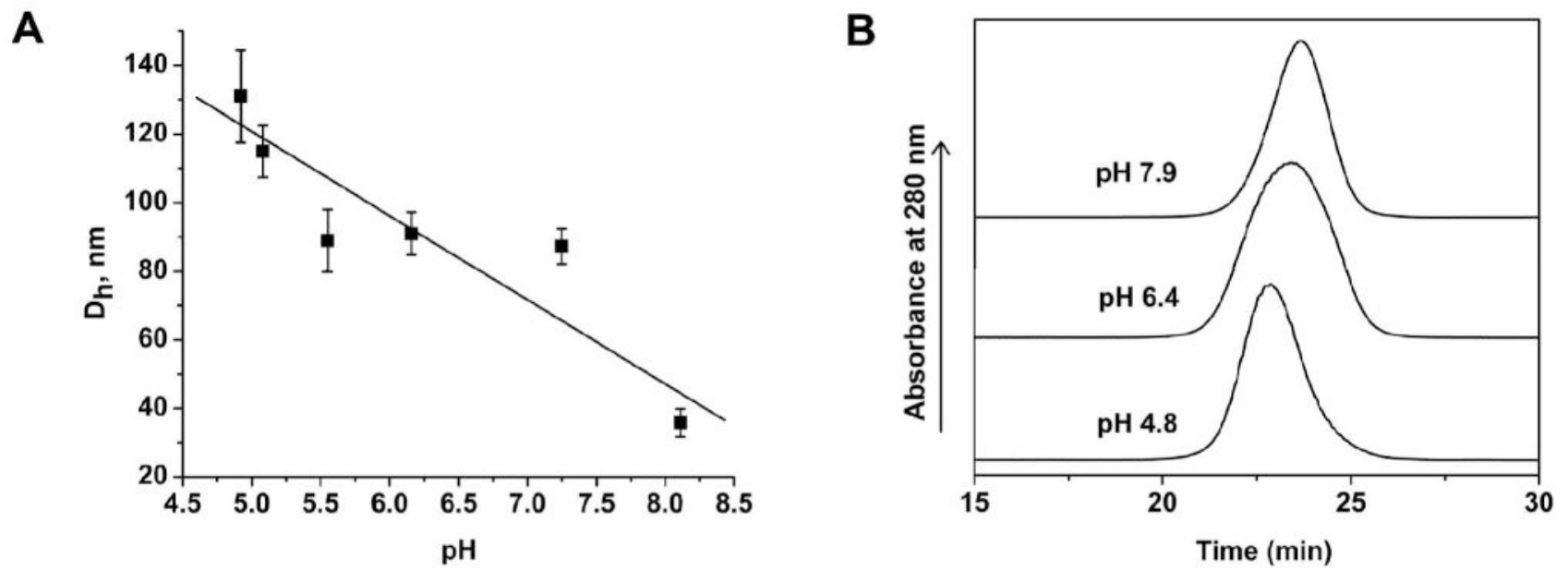

Figure 4.

Studies on the dependence of polymeric Au(I)SG precursor size on $\mathrm{pH}$. A. Hydrodynamic radius at different $\mathrm{pH}$ values of the polymeric $\mathrm{Au}(\mathrm{I}) \mathrm{SG}$ precursors measured using DLS. Error bars are standard deviation of three trials. B. The size exclusion chromatograms of the polymeric $\mathrm{Au}(\mathrm{I}) \mathrm{SG}$ precursors at $\mathrm{pH} 4.8,6.4$, and 7.9 with retention times of $22.9,23.4$, and $23.7 \mathrm{~min}$, respectively. The precursors were separated using Superose 6 column with $10 \mathrm{mM}$ phosphate or acetate buffered saline as the elution buffer. 


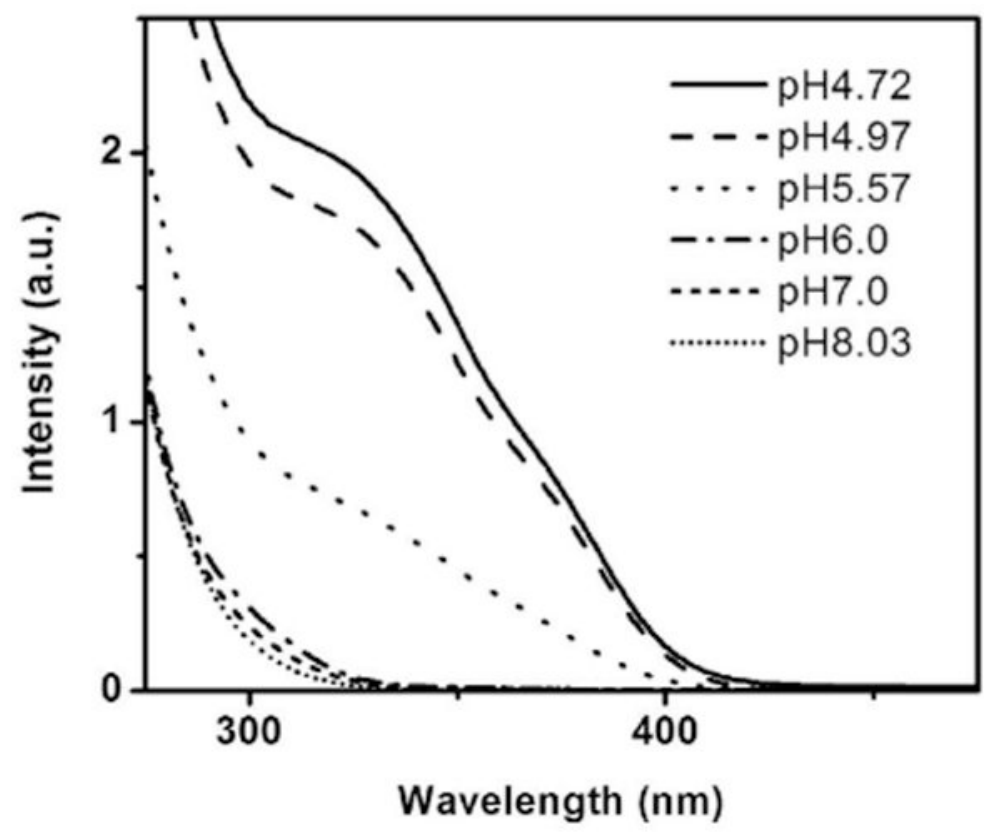

Figure 5.

$\mathrm{UV}-\mathrm{Vis}$ spectra of the polymeric $\mathrm{Au}(\mathrm{I}) \mathrm{SG}$ precursor at different $\mathrm{pH}$ values. 



Figure 6.

A: TEM micrograph of His-tagged Ad12 knob proteins labeled with Au NP coated with GSH/ Lys-Ni-NTA-SH (negatively stained). Inset: Higher magnification image of the core-shell structure formed between the knob proteins and Au NP. Arrows indicate the position of the knob proteins around the black dot (Au NP). B: TEM micrograph of the mixture of non-Histagged Ad12 knob proteins and Au NPs. Both images are shown in the same scale. 

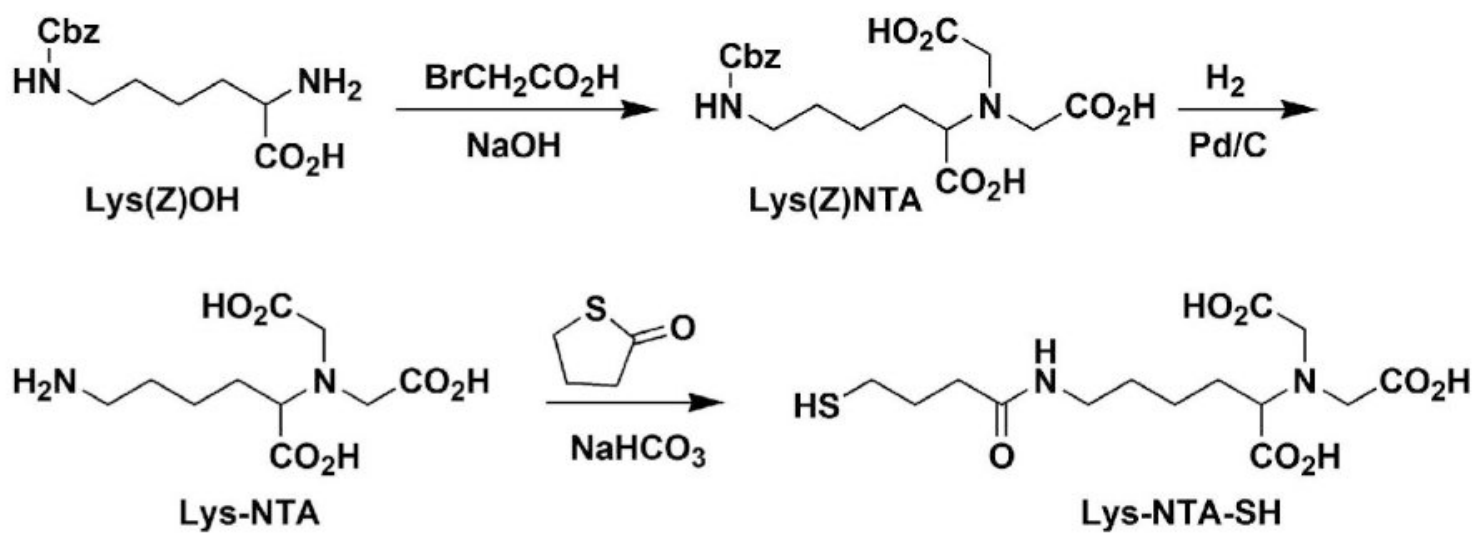

Scheme 1.

Synthesis of Lys-NTA-SH. 


<smiles>CC(C)(C)C#CC(=O)NCC(=O)NC(Sc1ccc(SCCCC(=O)NCCCCCC(C(=O)O)N(CC(=O)O)CC(=O)O)cc1)C(=O)NC(=O)CCC(N)C(=O)O</smiles>

Scheme 2.

Synthesis of Au NPs. A. Au NP coated with GSH only; B. Au NP coated with 3:1 mixture of GSH and Lys-NTA-SH. Reaction conditions: i. $\mathrm{HAuCl}_{4}$, ii. Adjust pH, iii. $\mathrm{NaBH}_{4}$. 
(1) $\mathrm{Au}^{+3}+3 \mathrm{GSH} \longrightarrow \mathrm{Au}(\mathrm{I}) \mathrm{SG}+\mathrm{GSSG}$

(2) $\mathrm{n} \mathrm{Au}(\mathrm{I}) \mathrm{SG} \longrightarrow[\mathrm{Au}(\mathrm{I}) \mathrm{SG}]_{\mathrm{n}}$ polymeric form

(3) $[\mathrm{Au}(\mathrm{I}) \mathrm{SG}]_{\mathrm{n}} \stackrel{\mathrm{NaBH}_{4}}{\longrightarrow} \mathrm{Au}^{0}[\mathrm{Au}(\mathrm{I}) \mathrm{SG}]_{\mathrm{n}-1}$
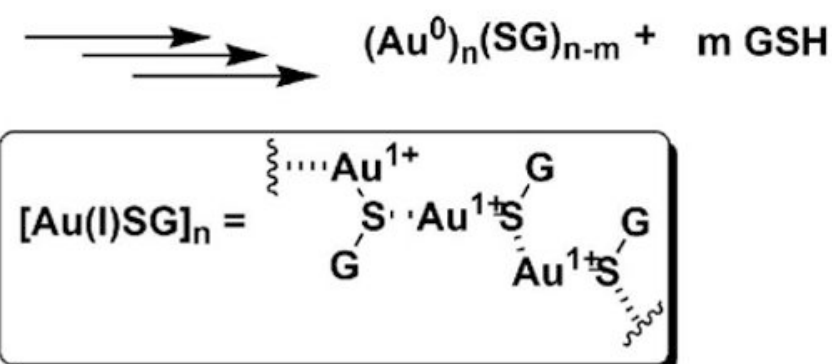

Scheme 3.

Proposed mechanism for the formation of $\mathrm{Au}$ NP from $\mathrm{Au}^{3+}$ and GSH. 

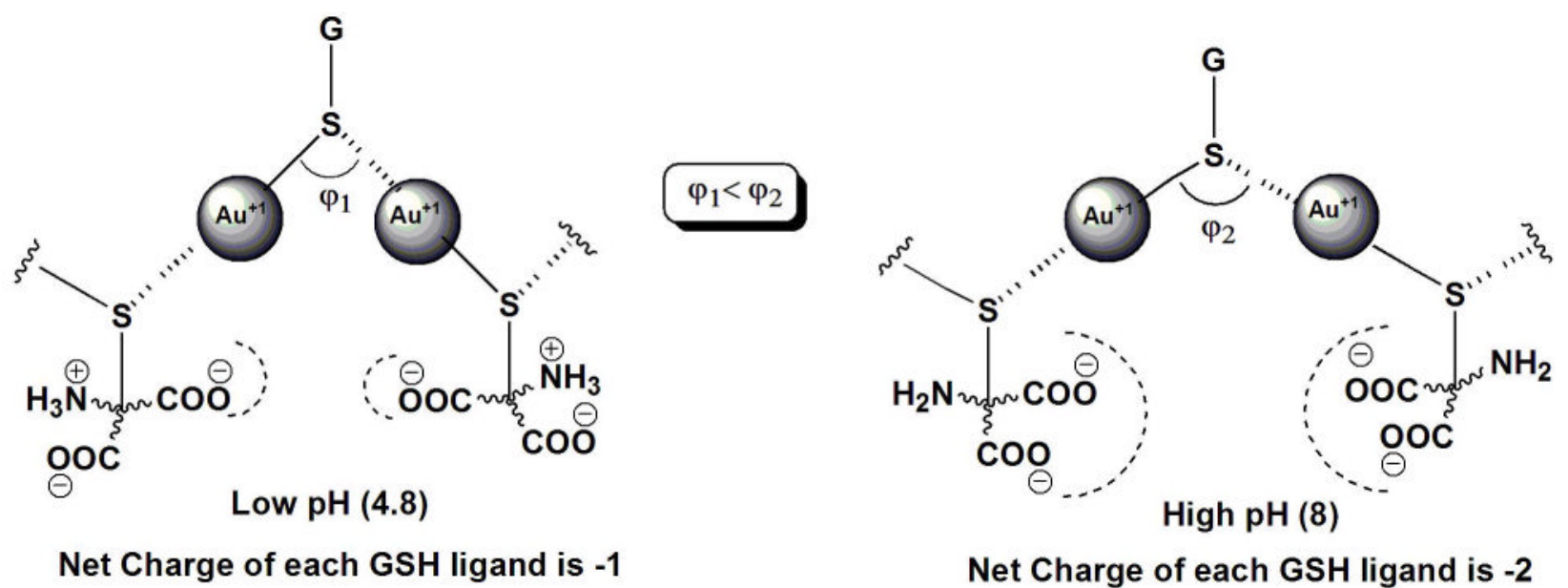

Net Charge of each GSH ligand is $\mathbf{- 2}$

Scheme 4.

An illustration of the dependence of the Au-S-Au angles and the corresponding intramolecular forces of the NP precursor on $\mathrm{pH}$. 


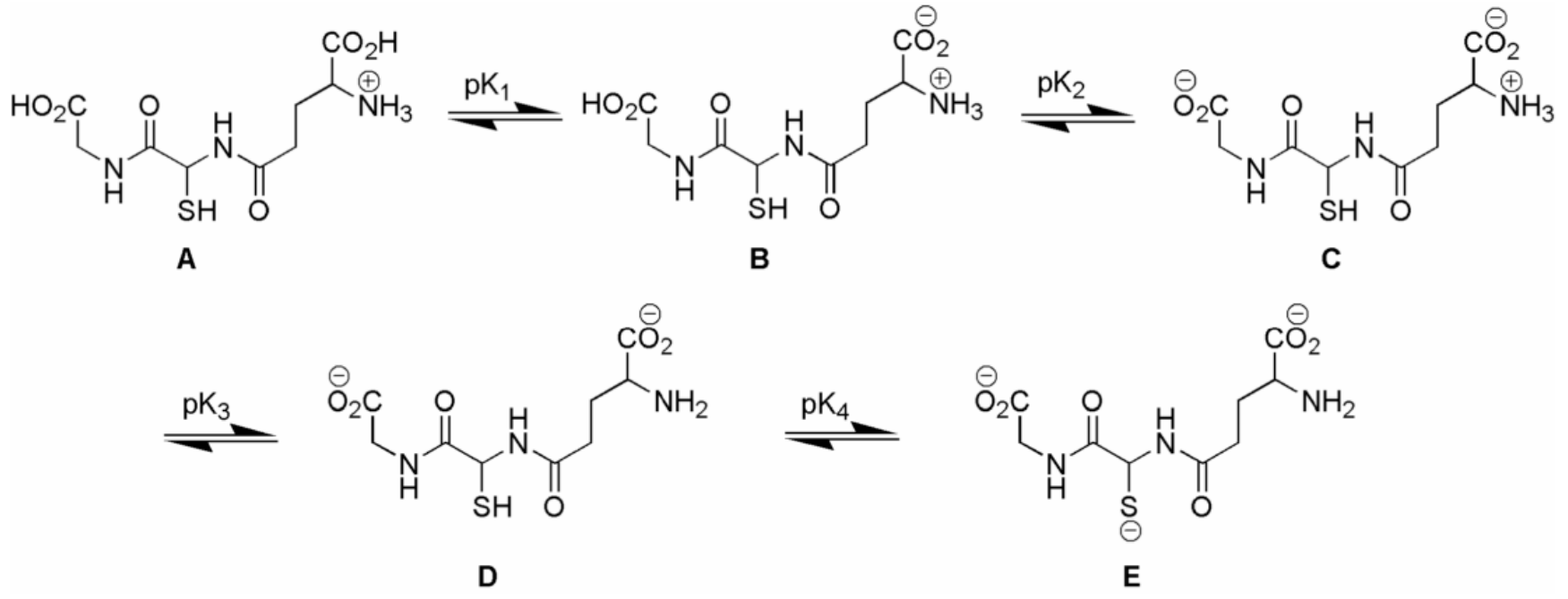

Scheme 5.

The ionization of GSH. The $\mathrm{pK}_{1}, \mathrm{pK}_{2}, \mathrm{pK}_{3}$, and $\mathrm{pK}_{4}$ values are 2.12, 3.53, 8.66, and 9.62, respectively (Reference 40). 

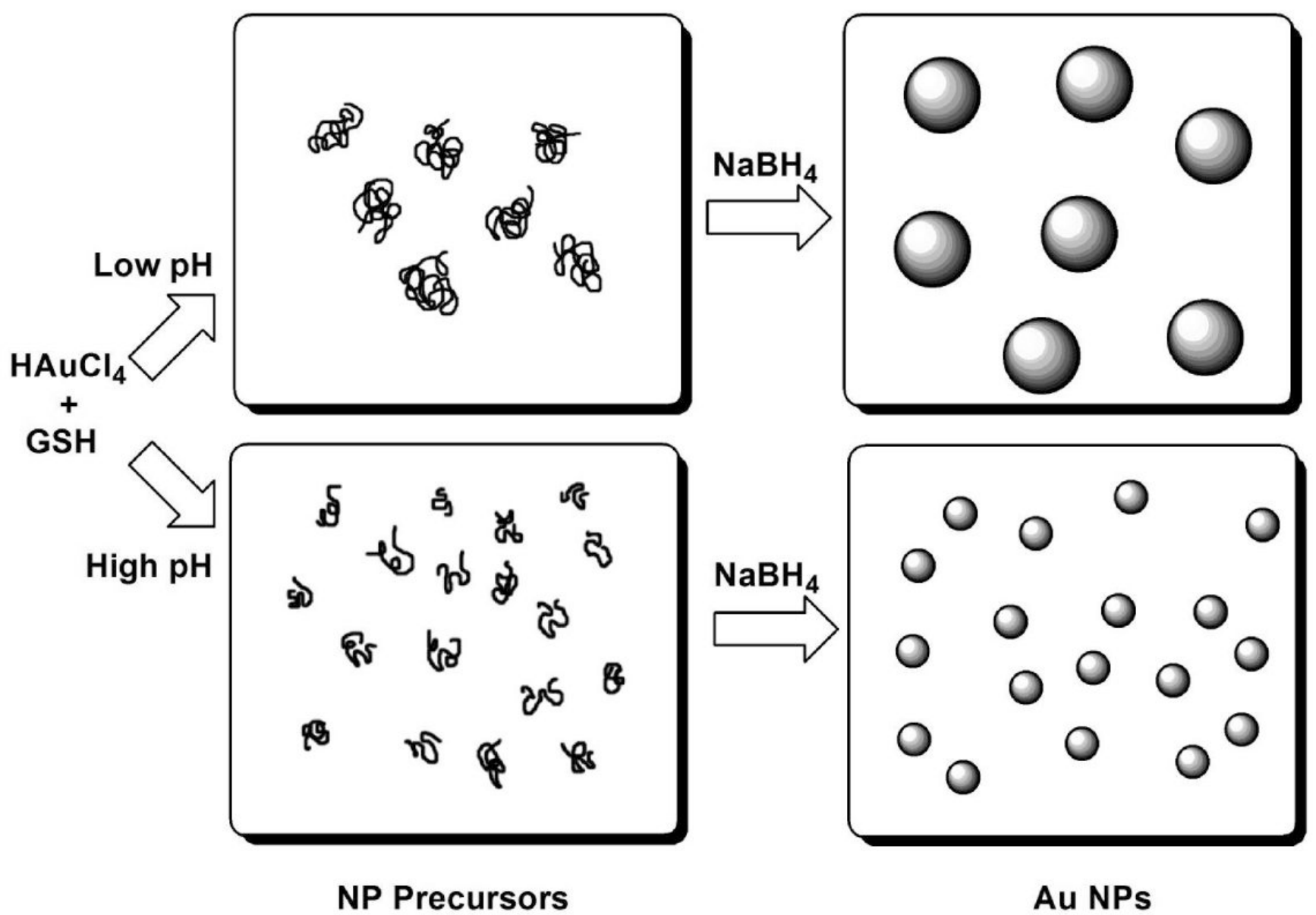

Scheme 6.

A schematic representation of the proposed mechanism of the formation of size-controllable Au NPs capped with GSH. 




Scheme 7.

The binding reaction between a His-tagged protein and the Au NP functionalized with NiNTA. 